\title{
Solicitación y abusos en los monasterios femeninos de Indias a inicios del siglo XVII: una aproximación ${ }^{7}$ \\ Solicitation and Abuses in the Women's Monasteries of Indies at the beginning of the 17 $7^{\text {th }}$ century: An Approximation
}

\section{Francisco José García Pérez}

Universitat de les IIles Balears-IEHM

ESPAÑA

garcia.franj@hotmail.com

[Hipogrifo, (issn: 2328-1308), 7.2, 2019, pp. 395-407]

Recibido: 05-05-2018 / Aceptado: 10-08-2018

DOI: http://dx.doi.org/10.13035/H.2019.07.02.31

Resumen. El estudio de las distintas trasgresiones de la vida monástica femenina a lo largo de la Edad Moderna parece vivir días prósperos. Actualmente, contamos con trabajos que aportan nueva luz sobre asuntos tan controvertidos, pero a la vez tan presentes, como el quebrantamiento de la clausura, el abandono de la vida en común y, por supuesto, la solicitación en los confesionarios de monjas. Teniendo lo anterior en cuenta, este artículo pretende sacar a relucir, en primer lugar, la existencia de desmanes y abusos que se repetían en numerosos monasterios femeninos de la América postridentina. A continuación, se pondrá énfasis en algunos casos particulares de obispos que intentaron implantar la estela del Concilio en sus respectivas diócesis, abriendo el camino a unas reformas que, por supuesto, fueron finalmente asumidas por sus sucesores durante el siglo XVIII.

Palabras clave. Concilio de Trento; monasterios; clausura, solicitación.

1. Este artículo se ha realizado en el marco de una beca posdoctoral «Margalida Comas» concedida por el Govern de les Illes Balears y cofinanciada por el Fondo Social Europeo a través del Programa Operativo del FSE de las Illes Balears para el período 2014-2020 
Abstract. The study of the different transgressions of the feminine monastic life throughout the Modern Age seems to live prosperous days. Currently, we have works that bring new light on controversial issues, but at the same time so present, such as the breaking of the closure, the abandonment of life in common and, of course, the solicitation in the confessions of nuns. Bearing this in mind, this article aims to highlight, in the first place, the existence of excesses and abuses that were repeated in numerous female monasteries in post-Tridentine America. Next, emphasis will be placed on some cases of bishops who tried to implant the stele of the Council in their respective dioceses, opening the way to reforms that, of course, were finally assumed by their successors during the eighteenth century.

Keywords. Council of Trent; Monasteries; Clousure; Solicitation.

\section{LA REFORMA TRIDENTINA Y SU DIFÍCIL IMPLANTACIÓN EN EL NUEVO MUNDO}

La estela de una necesaria reforma para los monasterios femeninos de la América española no nació en las sesiones de Trento². En la Castilla de Isabel I, hubo ya proyectos de reforma en numerosos monasterios de monjas dirigidos por el cardenal Cisneros, que marcaron la hoja de ruta para muchas de las nuevas fundaciones $^{3}$. De igual modo, a lo largo del siglo XVI, y conforme avanzaba la conquista del territorio americano, distintos obispos de Indias incidieron en la necesidad de purgar unos excesos que, por supuesto, ya se vivían en la Europa católica y parecían repetirse también allíi. Sin embargo, es tras el Concilio de Trento cuando se observa un verdadero punto de inflexión en la historia de la Iglesia indiana, conflgurándose una auténtica reforma capaz de purgar los desmanes heredados del pasado medieval y construir unos cimientos que pasarían a la posteridad como la Iglesia de la Contrarreforma 5 .

En sus numerosas sesiones, Trento diseñó el modo de vida que debían practicar las órdenes religiosas y, por supuesto, también las monjas ${ }^{6}$. A partir de entonces, se reforzaban y confirmaban cuatro votos inalterables que suponían los pilares básicos de la vida monacal femenina: los votos de pobreza, obediencia, castidad y clausura ${ }^{7}$. En efecto, Trento consideraba prioritario forzar a las religiosas a recluirse en sus respectivos monasterios, quedando privadas de cualquier contacto con el mundo exterior, viviendo una vida alejada de lujos y permaneciendo sujetas a una autoridad exterior que velara por su buen gobierno -ya fuese tuteladas por un obispo o un superior de la rama masculina de la orden-8. Asimismo, se hacía espe-

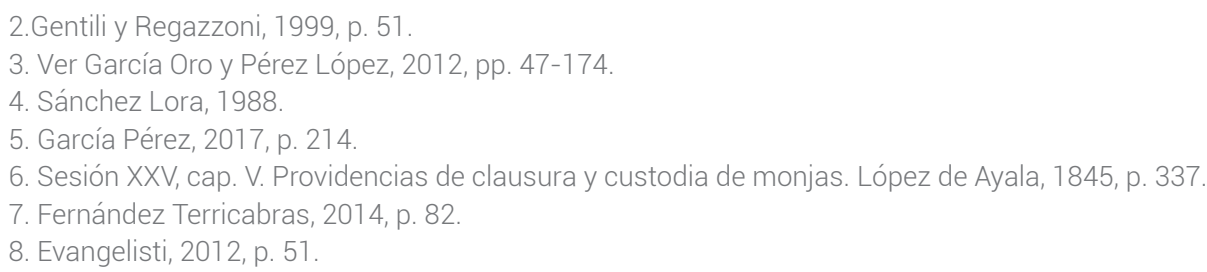


cial hincapié en la vida en común como medio más eficaz para evitar unos abusos que, por supuesto, no eran nuevos.

El caso americano tiene una serie de peculiaridades con respecto, por ejemplo, a la España de Felipe $\|{ }^{9}$. Antes de Trento, los distintos virreinatos de Indias contaban ya con numerosos monasterios femeninos. La progresiva expansión territorial y la conquista de nuevas zonas llevaba implícita la fundación de más comunidades de monjas. Y si bien es cierto que estas no fueron, ni de lejos, igual de numerosas que las masculinas, también estuvieron presentes allí. Sin embargo, el Concilio incentivó todavía más las nuevas fundaciones, dándose a finales del siglo XVI un verdadero incremento de monasterios femeninos ${ }^{10}$. Teniendo esto presente, los nuevos cenobios se erigieron respetando ya el modelo tridentino de vida monástica. Dotados la mayoría de ellos con una única entrada, amplias zonas de vida comunitaria y altos muros, se perseguía así un cumplimiento estricto de los cuatro votos.

Al mismo tiempo, la América española se vio inundada de tratados y manuales que aleccionaban a las religiosas sobre el perfecto modo de vida que debían practicar, valiéndose muchas veces de modelos de santidad femenina y de los mismos preceptos que Trento había establecido. La mayoría de los conservados actualmente son posteriores a 1650, pero reflejan unas ideas que se estaban difundiendo por todas partes desde mucho antes. De hecho, cuando el teólogo moral fray Luis Lozano escribió su Espejo de monjas a finales de la centuria, aleccionaba a todas las religiosas basándose precisamente en obras anteriores. Hablando de la clausura, recordaba que su quebrantamiento era «un pecado mortal, de inobediencia, contra precepto Eclesiástico» ${ }^{11}$. 0, como advertía fray Raimundo Lumbier en 1680, cualquier priora o portera de monasterio que no vigilase con celo la vida en clausura, «incurren en descomunión mayor reservada [...] que dan lugar a que entren dentro la clausura los que ni deben ni hay causa útil ni necesaria» ${ }^{12}$. Además, algunas monjas participaron también de este deseo de vigorizar la vida de clausura y mantener intacto el espíritu de la reforma tridentina. Destacan, por supuesto, los escritos de Santa Teresa, que incidían, entre otras cosas, en un espíritu de renuncia e incluso de mortificación del cuerpo como medio para purgar las propias tentaciones humanas ${ }^{13}$.

Pero lo cierto es que conseguir la definitiva implantación de los preceptos tridentinos no fue fácil en absoluto. Cada vez son más los trabajos que han sacado a colación esta realidad, especialmente en lo que se refiere a los monasterios de monjas $^{14}$. Superando un discurso tradicional que hacía pensar que las comunida-

9. Sobre la implantación de la reforma católica en los monasterios femeninos de la España de Felipe II ver Atienza López, 2014, pp. 812 y ss.

10. Borges, 1992, p. 269

11. Lozano, Claro espejo de monjas, p. 22

12. Lumbier, Fragmentos varios morales en prosecución de los que están en la «Suma» de Arana, p. 12. 13. Herraiz García, 1980, p. 149.

14. Algunos ejemplos sobre la resistencia femenina a las reformas tridentinas son Atienza López, 2014, pp. 807-834; García Pérez, 2017, pp. 211-232; Sánchez Hernández, 1998, pp. 69-105; Echániz Martínez, 2012, pp. 275-295. 
des de religiosas se plegaron siempre a aceptar el nuevo modelo de vida que se tenía preparado para ellas, muchas veces hubo una resistencia activa. De hecho, las causas que motivaban esta oposición a la clausura no pueden reducirse únicamente a una ${ }^{15}$.

Primeramente, no todas las mujeres que ingresaban en la vida monástica mostraban siempre una vocación sincera ${ }^{16}$. Esta idea es fundamental para comprender la existencia de abusos en distintos monasterios como la violación de la clausura, el abandono de la vida en común o, por supuesto, la solicitación. Dejando de lado que hubo mujeres que se recluyeron buscando imitar los distintos modelos de santidad femenina, otras muchas eran forzadas a tomar los hábitos. La elevada mortalidad masculina como consecuencia de la conquista, las enfermedades o las revueltas que poblaron la primera mitad del siglo XVI, además de las dificultades para pagar la dote del casamiento - sensiblemente más elevada que la que se pagaba para ingresar en un monasterio- y las presiones familiares para deshacerse de bocas que alimentar, sin duda contribuyeron a engrosar las filas del clero femenino. De hecho, el fraile carmelita fray Isidoro de la Asunción ponía énfasis tras su visita a los conventos de su orden en Nueva España en la sobresaturación de monjas en ellos, precisamente por motivos ajenos a la vocación religiosa ${ }^{17}$.

Otra de las causas que incitaba a las religiosas a violar sus votos venía desde el exterior de aquellos monasterios. A inicios del Seiscientos, eran muchos los obispos en Indias que denunciaban a la Corona la persistente relajación que se experimentaba entre las órdenes masculinas y el clero en general18. En 1589, el obispo de Cuzco escribía recién llegado a su diócesis sobre la desesperada situación que allí se vivía, con «algunos singulares que le escandalizaran de manera que obligara al remedio eficaz y castigo ejemplar, particularmente redundando en tanto daño de la conversión y manutención de la fe» ${ }^{19}$. Asimismo, un provincial agustino certificaba el desbordante quebrantamiento del celibato entre los regulares del extenso virreinato novohispano y las Filipinas, que «es cosa de vicios sensuales. Remédielo Dios que el que V.M. enviare se admirará de ver cuán suelto anda el diablo» ${ }^{20}$.En efecto, había casos sobrados de religiosos que se adentraban en los monasterios de monjas con muy diversos fines. En la Encarnación de Popayán, por ejemplo, se supo que «las monjas y los frailes [...] andaban por el convento y cada uno llevaba su monja a su celda» ${ }^{21}$. De hecho, Trento no consiguió erradicar completamente una sexualidad activa especialmente constatada entre el clero masculino. Como se verá a continuación, los delitos de solicitación y amancebamiento que llegaron a los tribunales inquisitoriales poblaron todo el territorio hispanoamericano a lo largo de la Edad Moderna, sin finalmente conseguir su erradicación ${ }^{22}$. Y, por supuesto,

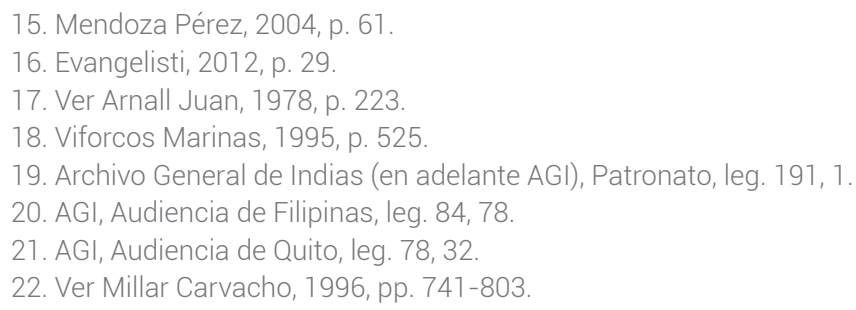


este quebrantamiento del voto de castidad por parte de frailes y clero secular tuvo su repercusión de muy diversos modos en los monasterios de monjas.

Lo más común eran las visitas que distintos religiosos hacían a los cenobios buscando favores de diversa índole. Esta práctica de seducción y galanteo fue muy común durante el siglo XVII, llegando a construirse el arquetipo de la «monja enamorada» ${ }^{23}$. En muchas ocasiones, las religiosas, retratadas socialmente como un símbolo de pureza y virginidad, se convertían en un objetivo muy atractivo para hombres que no cumplían con sus respectivos deberes religiosos ${ }^{24}$. Por ello, los obispos de Indias recibieron continuamente denuncias de este tipo. Hacia 1616, el obispo de Popayán escribía a Felipe III sobre un monasterio de monjas bajo su jurisdicción y «la poca clausura de él y la facilidad que había en poder saltar las tapias por ser muy bajas» ${ }^{25}$. A menudo, la clausura se quebrantaba también con la asistencia de familiares y amigos de las religiosas al interior de los monasterios ${ }^{26}$. Algunas monjas jóvenes acudían en secreto a la portería para encontrarse con apuestos caballeros que las cortejaban. Y los claustros de los monasterios eran también el escenario de improvisadas danzas o bailes. Pero si hubo una situación que preocupó sobremanera a los obispos tridentinos y que terminó convirtiéndose en uno de los campos de actuación más peliagudos del Santo Oficio tras su implantación, fue la solicitación.

Este delito no era un asunto nuevo. Mucho antes de Trento, se tenía constancia de que en los confesionarios de la Europa medieval a menudo se producían este tipo de situaciones que, en esencia, se traducían en la demanda de favores sexuales por parte del confesor a sus penitentes. La eliminación de dicha práctica fue ciertamente imposible, debido a que la Iglesia tardomedieval no contaba con mecanismos suficientes para erradicarla y, en otras ocasiones, los mismos obispos y superiores de las órdenes religiosas simplemente cerraban los ojos ante aquella realidad. Sin embargo, la solicitación tomó un cariz importantísimo en las sesiones del Concilio de Trento. Teniendo presente que el sacramento de la confesión había sido regulado al detalle, puede suponerse que el Papado se preocupó sobremanera de la existencia de confesores solicitantes ${ }^{27}$. Es por esto por lo que se tomaron diversas medidas para atajar una lacra que pesaba sobre aquella Iglesia desde tiempo pretéritos.

Primero, se delegó su persecución a los tribunales inquisitoriales. En España, el Santo Oficio se adjudicó la represión de clérigos solicitantes desde $1592^{28}$. En algunas zonas de Indias, especialmente en la denominada como «tierra de frontera», los brazos de la Inquisición tardaron aún algunos años en actuar, asumiendo todavía los respectivos obispos la represión del delito. Lo verdaderamente importante, sin embargo, no era tanto el tribunal que se ocuparía de erradicar dicha práctica, sino

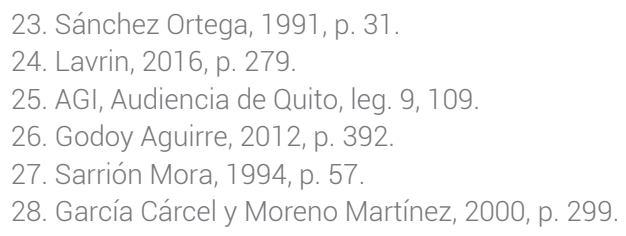


perfilar la compleja definición de qué actos estaban incluidos en el delito de solicitación o cuáles eran los mecanismos más efectivos para detectar a los culpables. Por ello, el papa Gregorio XV publicó en 1622 la bula Universi Dominici Gregis, en la que quedaban establecidas las características del delito de solicitación ${ }^{29}$. Conversaciones demasiado sugerentes, cualquier contacto físico, insinuaciones directas o incluso el que el confesor solicitase favores sexuales a su confesada a través de una tercera persona estaban incluidos en el delito de solicitación ${ }^{30}$.

Como puede suponerse, los distintos virreinatos americanos no fueron una excepción y también allí se constató la sombra de la solicitación en los confesionarios de monjas. De hecho, gran parte de la historiografía que ha estudiado estos fenómenos de quebrantamiento de la vida monástica ha centrado su prisma en el siglo XVIII, especialmente durante las grandes reformas de Carlos III. Pero lo cierto es que, a inicios del Seiscientos, algunos prelados de Indias intentaron ya atajar aquellos abusos.

\section{TRASGRESIONES DE LA VIDA MONACAL FEMENINA E INTENTOS DE REFORMA}

El Concilio de Trento había ordenado a todos los prelados católicos que «procuren con el mayor cuidado restablecer diligentemente la clausura de las monjas en donde estuviere quebrantada» ${ }^{31}$. Los obispos de Indias también acataron la voluntad de los padres conciliares y se dispusieron a implantar dichos preceptos en sus respectivas diócesis, pero por supuesto se hallaron con innumerables frenos para conseguir tales objetivos ${ }^{32}$. De hecho, la mayoría de las veces, numerosos obispos obcecados en erradicar abusos y excesos intolerables para la Iglesia de la Contrarreforma terminaban siendo retratados ante sus feligreses como auténticos tiranos, más interesados en su propio provecho que en alcanzar su misión pastoral. Esto se explica, en parte, por los innumerables obstáculos que minaban la autoridad diocesana ${ }^{33}$. Los Cabildos catedralicios suponían un contrapoder efectivo a las aspiraciones del episcopado, las órdenes masculinas a menudo se declaraban en rebeldía, respondiendo únicamente ante sus respectivos superiores, y en el caso de los monasterios femeninos, la mayoría de las monjas trasgresoras solían respaldarse en sus propios lazos familiares para huir de la ira episcopal. Quizás esto justifique más claramente porqué fue tan difícil implantar los preceptos tridentinos $y$, al mismo tiempo, porqué se dieron tantos desmanes en los cenobios de religiosas de la América colonial.

29. Haliczer, 1998, p. 76.

30. González Marmolejo, 2002, p. 26

31. Sesión XXV, cap. V. Providencias de clausura y custodia de monjas. López de Ayala, 1845, p. 337.

32. Los obispos de Indias contaban con estrategias de diversa índole para asegurarse que se mantenía vigorosa la reforma tridentina en sus respectivas diócesis. Primeramente, estaban los concilios provinciales, celebrados cada tres años a fin de corregir excesos y restaurar la disciplina. En segundo lugar, los prelados realizaban visitas a las diócesis, pues era el modo más eficiente de comprobar que se cumplía la voluntad episcopal. Y, finalmente, estaban los sínodos diocesanos, convocados normalmente cada año por los obispos para tratar los asuntos religiosos bajo su jurisdicción. Ramírez, 2013, p. 45.

33. Castañeda Delgado y Marchena Fernández, 1992, p. 227. 
En algunos territorios, la Inquisición había comenzado a trabajar desde muy pronto. Es el caso del virreinato de Nueva España. A inicios del siglo XVII, el Tribunal del Santo Oficio de ciudad de México había recopilado ya los primeros casos de solicitación en distintos confesionarios de monjas. Tenemos el ejemplo paradigmático del monasterio de Santa Clara de ciudad de México, donde el confesor había seducido a una de las religiosas y mantenía relaciones sexuales con ella en el espacio del confesionario. Ambos fueron severamente juzgados por la Inquisición por delitos de solicitación y alumbramiento ${ }^{34}$.

Sin embargo, en muchos otros territorios de la extensa América colonial española, los obispos inmediatamente posteriores a la celebración del Concilio de Trento se adjudicaban todavía la persecución de frailes solicitantes y monjas trasgresoras en sus respectivas diócesis ${ }^{35}$. De hecho, se observa claramente un aumento del intervencionismo diocesano en este tipo de cuestiones, asumiendo las directrices tridentinas y ambicionando construir diócesis totalmente alejadas de aquellos abusos tan comunes y, por lo que parecía, tan difíciles de extirpar. Debe tenerse también presente que numerosos obispos estaban cada vez más celosos de su propia autoridad y se valían de rumores y denuncias de transgresiones -a veces infundados y producto de redecillas dentro del monasterio en cuestión- para fortalecer todavía más su poder sobre los monasterios bajo su jurisdicción.

En la isla de Santo Domingo, el obispo fray Cristóbal Rodríguez Juárez tomó una actitud muy beligerante para mantener una intachable virtuosidad en los monasterios de monjas, especialmente entre las clarisas, imponiendo severos castigos contra algunos frailes que intentaron violar la clausura ${ }^{36}$. Asimismo, en el Panamá de principios del siglo XVII, el obispo fray Francisco de la Cámara ejerció una despiadada política de castigos contra el monasterio de la Concepción de dicha ciudad, por considerar que allí se vivía una relajación a sus ojos intolerable. Llevando al extremo su disciplina, y según contaba la misma priora del monasterio, una vez reunidas «en capítulo nos llamó mujeres de la manflota y otras injurias y afrentas» ${ }^{37}$. Al mismo tiempo, sometió a muchas religiosas a «azotes y castigo [...] y desnudas las espaldas, a otras metió en cepos, a la que acabó de ser abadesa el trienio pasado la prendió y secuestró sus camisas y hábitos» ${ }^{38}$. Todo indica, en este caso, que el obispo de la Cámara pretendía llevar al extremo las disposiciones tridentinas, forzando a aquellas religiosas a vivir una vida de total renuncia mundana y dedicada por entero al servicio religioso. Y, además, fortalecía de ese modo su propia autoridad episcopal, valiéndose de las monjas concepcionistas como ejemplo aleccionador para el resto de los monasterios bajo su jurisdicción.

\section{Lavrin, 2016, p. 300.}

35. En el caso del virreinato de Perú, el tribunal del Santo Oficio en Lima se había establecido ya en 1570, pero su jurisdicción todavía se estaba implantando a inicios del siglo XVII. De hecho, obispos como el de Popayán o Quito actuaban en los casos de solicitación, que posteriormente pasarían a depender ya directamente de la Inquisición. Millar Carvacho, 1996, 743.

36. AGI, Audiencia de Santo Domingo, leg. 869, 6.

37. AGI, Audiencia de Panamá, leg. 17, 2

38. AGI, Audiencia de Panamá, leg. 17, 2 
Sin embargo, algunos de los casos que mayormente resonaron a inicios del siglo XVII tuvieron lugar en el extenso virreinato del Perú. En 1609 llegaba a la diócesis de Popayán el obispo fray Juan González de Mendoza, miembro de la orden agustina ${ }^{39}$. Hombre de fuerte carácter y repleto de una incuestionada autoridad personal, se había propuesto desde su inmediato arribo limpiar su diócesis y edificar moralmente a los miembros de su clero -intentando también llenar las empobrecidas arcas episcopales-. Ese mismo año, conoció de primera mano la delicada situación que se estaba viviendo en el monasterio de monjas de la Encarnación, bajo su jurisdicción ${ }^{40}$. Desde hacía algunos años, la priora, sor Gabriela de la Encarnación, mantenía una relación amorosa con un dominico, protagonizando recurrentes encuentros furtivos dentro del monasterio ${ }^{41}$. Con el paso del tiempo, más miembros de la orden de Santo Domingo se sintieron tentados a participar de estas visitas a las agustinas, atrayendo incluso la atención de vecinos seculares de Popayán. El año de 1609, la facción que arropaba a la priora había continuado con aquellos amoríos, hasta el punto, como informó el oidor de la Audiencia de Quito, de «haber parido ocho monjas y una de ellas parió estando yo aquí en la comisión y averigüé el parto y ella misma lo confesó, aunque no supo afirmarse en quien era el padre» ${ }^{42}$.

Enterado de todo, González de Mendoza pidió ayuda a los magistrados de la Audiencia e impuso un severo castigo a los implicados en lo que fue conocido como el 'sacrilegio de la Encarnación'. Trasladado personalmente al monasterio, el obispo organizó un improvisado juicio y, si creemos en lo que dicen algunas fuentes, llegó a límites extremos para conseguir algunas confesiones, «todo a fin de querer averiguar qué devotos han entrado en aquel convento que ha puesto grandísima admiración y espanto» ${ }^{43}$. Finalmente, y con el beneplácito de Felipe III, el obispo de Popayán tomó la drástica e impopular medida de que «las saquéis [a las quince monjas culpables] del dicho convento y repartáis por otros de esa provincia, las de Quito, Nuevo Reino y Perú haciendo traer unas [monjas] de otras partes, [...] de buena vida y costumbres con cuyo gobierno virtud y ejemplo se reparen los daños pasados» ${ }^{44}$.

En cuanto a los dominicos implicados, González de Mendoza exigió al provincial de la orden que impusiese un castigo ejemplar para ellos, llegando a solicitar su destierro de las Indias, principalmente porque habían engañado a las monjas con la idea de que «podían con toda conciencia salirse de la clausura cuando se les antojase y castas por ser inválidos los votos que profesaron en manos del ordinario"45. Sin embargo, el obispo pronto comprobó de primera mano los obstáculos inherentes a la autoridad episcopal ${ }^{46}$. El gobernador payanense, según informó el prelado a Madrid, «ha puesto sumo cuidado y diligencia en procurar que los dichos culpados

39. Ver Viforcos Marinas, 1998, pp. 729-758.

40. Viforcos Marinas, 1995, p. 532.

41. Martínez Cuesta, 1995, p. 606

42. AGI, Audiencia de Quito, leg. 9, 109.

43. AGI, Audiencia de Quito, leg. 86, 2.

44. AGI, Audiencia de Quito, leg. 78, 32.

45. AGI, Audiencia de Quito, leg. 78, 35.

46. Sobre las políticas de los obispos en Indias y las órdenes religiosas, ver Ramírez, 2013, pp. 39-82. 
sean dados por libres, así por habérselo prometido como por estar de ellos prendado con dádivas y otros jueces» ${ }^{47}$. Los mismos lazos de clientelismo y parentesco que se repetían en toda la sociedad indiana estaban presentes también en Popayán.

La ciudad de Quito tampoco estuvo exenta de episodios que demostraban la pervivencia de unos abusos que, por supuesto, también incluían el delito de solicitación, la violación de la clausura y el abandono de la vida en común. En 1607, el obispo fray Salvador de Ribera y Dávalos recibió una denuncia por parte de la priora de las dominicas de Santa Catalina de Sena. El prior del monasterio vecino de San Pedro Mártir, fray Reginaldo Gamero, había abusado de su autoridad de confesor para obtener favores sexuales de algunas monjas, llegando, en palabras de la priora, al «gravísimo exceso y sacrilegio detestable que en el dicho mi convento ha cometido [...] con cierta religiosa de nuestro convento con notabilísimo escándalo»48.

En aquel momento, fray Reginaldo Gamero estaba a punto de ser elegido como nuevo provincial. Este hecho, sumado a la constante indiferencia que el provincial en el cargo había mostrado hacia aquella cuestión -fray Francisco García era amigo íntimo de fray Reginaldo Gamero-, seguramente motivó a la priora de Santa Catalina de Siena a romper su silencio para dirigirse personalmente al obispo Ribera y Dávalos. Todo ello con la intención no solo de acabar con la carrera de Gamero, sino también de alejarle para siempre del monasterio. Algunos historiadores han intentado desmitificar los excesos cometidos por el religioso dominico, especialmente porque sigue siendo recordado como un hombre de gran cultura y erudición ${ }^{49}$. Pero lo que historiadores como fray José María Vargas no cuentan es que Gamero también visitaba otros monasterios de monjas al mismo tiempo. Es el caso de Santa Clara de Quito.

Por aquellas mismas fechas, fray Reginaldo Gamero mantenía una relación amorosa con la abadesa de las clarisas. A menudo se les veía reunidos en el compás del monasterio, y «cerradas las puertas en este lugar podían los susodichos muy a su salud hacer todo cuanto malquisieren, [...] y que en este mismo compás almorzaban y merendaban ${ }^{50}$. Con el tiempo, la superiora incitó a algunas de sus hermanas a participar de aquellas reuniones distendidas, mientras fray Reginaldo Gamero invitaba a otros dominicos quiteños a entrar también en Santa Clara. La situación llegó a tales niveles que, un día, el dominico y la abadesa de las clarisas hicieron reunir a toda la comunidad de monjas en el locutorio y, «estando allí todos juntos pidieron firmas para dejar la obediencia de nuestro P. San Francisco a las religiosas, que para aquello se habían juntado en el locutorio» ${ }^{51}$. Como puede suponerse, tal cantidad de quebrantamientos de la vida monástica terminó siendo conocida por el prelado. Y como en Popayán, el obispo Ribera y Dávalos aplicó una despiadada política de castigos a fin de acabar con unas situaciones que Trento condenaba abiertamente.

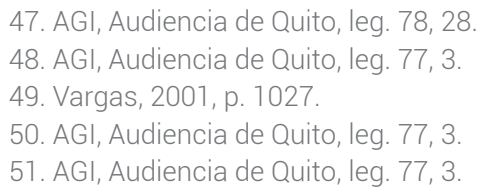


Cuando vio que el provincial de los dominicos, fray Francisco García, no solo toleraba las incursiones de los frailes de su orden en Santa Clara, sino que incluso apoyaba ciegamente la elección del padre Gamero para convertirse en su sucesor, el obispo lanzó una pena de excomunión contra ambos. Finalmente, fray Reginaldo Gamero huyó de la justicia a la ciudad de Lima y, según dicen algunos autores, terminó sus días en España ${ }^{52}$. El provincial de los dominicos fue públicamente castigado, siéndole arrebatado el hábito y quedando relegado a una vida en galeras. Y en cuanto a las monjas dominicas, se les impusieron durísimas censuras, «y no con el secreto que requerían las cosas de la religión» ${ }^{3}$.

Por supuesto, estos casos no fueron el final de una larga estela de abusos más allá de los muros de los monasterios femeninos. Todo lo contrario, el siglo XVII americano consolidó una doble realidad que iba a perpetuarse hasta la instauración de las ambiciosas reformas de Carlos III a partir de 1759. Por un lado, la Iglesia de la Contrarreforma continuó persiguiendo cualquier trasgresión de la vida monástica, valiéndose tanto de la asfixiante presencia de los tribunales inquisitoriales en Indias como de la reforzada autoridad de los obispos. Sin embargo, al mismo tiempo, siguieron dándose casos de monjas que violaron sus votos y quebrantaron la clausura de muy diversas formas, perpetuándose estos abusos en el tiempo sin ser jamás erradicados.

\section{CONCLUSIONES}

Los intentos de reformar los monasterios femeninos en la América española no nacieron con el Concilio de Trento. Sin embargo, es a partir de entonces cuando se observa una verdadera obsesión por implantar un modelo de vida monástica totalmente regulado al detalle. La historiografía centrada en el estudio del monacato femenino en Indias ha puesto mayormente su atención en el siglo xviii, y más concretamente en la época de reformismo de Carlos III, dejando de lado que aquello solo fue el culmen de un camino que se venía fraguando desde muchos años atrás. Porque, concluido Trento, distintos obispos de Indias intentaron poner freno a unas situaciones que, por supuesto, no eran nuevas, pero que parecían cada vez más incontrolables. La escalada de trasgresiones de la clausura, delitos de solicitación y relaciones sexuales que se vivieron en numerosos monasterios desde Quito y Popayán hasta Nueva España y las islas Filipinas, habían llegado a unos niveles ciertamente preocupantes. Es por esto por lo que la jerarquía eclesiástica asumió la estela tridentina como su baza y actuó con verdadera contundencia en sus respectivas diócesis.

En líneas generales, los prelados postridentinos optaron por medidas de castigo contundentes, que pretendían no solo atajar el mal de raíz, sino también reafirmar su propia autoridad y ascendencia entre todos los miembros del clero. Debe tenerse presente que, a inicios del siglo XVII, el brazo del Santo Oficio y sus perfeccionados métodos de persecución no estaban todavía implantados en numerosos territorios 
de los extensos virreinatos de Indias, lo cual llevaba a los obispos a adjudicarse la represión de estos delitos, valiéndose muchas veces de prácticas ineficaces para atajar aquel asunto. Mientras en ciudad de México la Inquisición comenzó a actuar desde finales del Quinientos, aún no funcionaba en muchas zonas del extenso virreinato de Perú. Por eso mismo, eran los prelados los encargados de perseguir la solicitación e imponer los preceptos tridentinos en los monasterios femeninos bajo su jurisdicción -aunque no siempre fuese así, como ocurrió con las clarisas y dominicas de Quito y fray Salvador de Ribera y Dávalos-. Y, aunque las medidas para atajar dichos abusos variaban de una diócesis a otra, el fin siempre era el mismo. Manteniendo vigorosos los muros conventuales, clausurando el máximo número de entradas al monasterio e incluso mortificando espiritual y corporalmente a las monjas trasgresoras, los prelados pretendían que estos desmanes no solo terminasen, sino que sirviesen de ejemplo aleccionador.

En definitiva, la idea que subyace es que el delito de solicitación, el quebrantamiento de la clausura y el amancebamiento reflejan la existencia de una sexualidad activa entre el clero femenino, totalmente condenada por la Iglesia de la Contrarreforma. Estos casos, lejos de ser aislados y excepcionales, se vivieron en numerosos cenobios de monjas del Nuevo Mundo. De tal modo que, más de un siglo después de los incidentes vividos en monasterios de ciudades como Quito o Popayán, los prelados de Indias continuaban persiguiendo dichas prácticas, haciendo así evidentes los límites que surgieron desde los mismos inicios de Trento.

\section{BiBLIOGRAFÍA}

Arnall Juan, María Josefa, «El Itinerario a Indias (1673-1679) del P. Fr. Isidoro de la Asunción, C.D. (Manuscrito 514 de la Biblioteca Provincial y Universitaria de Barcelona)», Boletín Americanista, 28, 1978, pp. 197-252.

Atienza López, Ángela, «Las grietas de la clausura tridentina. Polémicas y limitaciones de las políticas de encerramiento de las monjas... Todavía con Felipe IV», Hispania, 74, 248, 2014, pp. 807-834.

Borges, Pedro, Religiosos en Hispanoamérica, Madrid, Colecciones Mapfre 1492, 1992.

Castañeda Delgado, Paulino, y Marchena Fernández, Juan, La jerarquía de la Iglesia en Indias, Madrid Colecciones Mapfre 1492, 1992.

Echániz Martínez, Berta, «Una aproximación a la espiritualidad femenina en el Alicante de principios del siglo XVII», Feminismo/s, 20, 2012, pp. 275-295.

Evangelisti, Silvia, Storia delle monache, Bologna, II Mulino, 2012.

Fernández Terricabras, Ignasi, «La influencia del Concilio de Trento en las reformas descalzas», LibrosdeCorte.es, 9, 2014, pp. 81-86.

García Cárcel, Ricardo, y Moreno Martínez, Doris, Inquisición. Historia crítica, BarceIona, Temas de Hoy. Historia, 2000. 
García Oro, José, y Pérez López, Segundo L., «La reforma religiosa durante la gobernación del cardenal Cisneros (1516-1518): hacia la consolidación de un largo proceso», Anuarium Sancti lacobi, 1, 2012, pp. 47-174.

García Pérez, Francisco José, «La resistencia a la clausura en los monasterios femeninos de Mallorca durante el siglo XVIII», Espacio, Tiempo y Forma. Serie IV, Historia Moderna, 30, 2017, pp. 211-232.

Gentili, Antonio, y Regazzoni, Mauro, Storia della Spiritualità. La spiritualità della Riforma Cattolica, Bologna, Edizione Dehoniane Bologna, 1999.

Godoy Aguirre, Mario, «La música en los monasterios de la Real Audiencia de Quito», en Memorias del I Encuentro Internacional de Musicología, vol. I, ed. Mario Godoy Aguirre, Loja, Ministerio de Cultura, 2012, pp. 388-425.

González Marmolejo, Jorge René, Sexo y confesión: la Iglesia y la penitencia en los siglos XVIII y XIX, México D. F., Plaza y Valdés, 2002.

González Suárez, Federico, Historia general de la República de Ecuador. Tomo cuarto, Quito, Clásicos Ariel, 1969.

Haliczer, Stephen, Sexualidad en el confesionario. Un sacramento profanado, Madrid, Siglo XXI, 1998.

Herraiz García, Maximiliano, Solo Dios basta. Claves de la espiritualidad teresiana, Madrid, Triana, 1980.

Lavrin, Asunción, Las esposas de Cristo. La vida conventual en la Nueva España, México D. F., Fondo de Cultura Económica, 2016.

Lozano, Luis, Claro espejo de monjas, Madrid, por la viuda de don Juan del Barrio, 1699.

Lumbier, fray Raimundo, Fragmentos varios morales en prosecución de los que están en la «Suma» de Arana, Madrid, Imp. Pascual Bueno, 1680.

Martínez Cuesta, Ángel, «Las monjas en la América colonial, 1530-1824», Thesaurus. Boletín del Instituto Caro y Cuervo, 1.3, 1995, pp. 572-626.

Mendoza Pérez, Jesús Leticia, «El mundo novohispano del siglo XVII: claustro de la mujer criolla», Revista Géneros, 33, 2004, pp. 58-64.

Millar Carvacho, René, «El delito de solicitación en el Santo Oficio de Lima», Hispania Sacra, 48, 98, 1996, pp. 741-803.

Ramírez, Jessica, «Fundar para debilitar. El obispo de Puebla y las órdenes regulares, 1586-1606», Estudios de Historia Novohispana, 49, 2013, pp. 39-82.

Sánchez Hernández, María Leticia, «Las variedades de la experiencia religiosa en las monjas de los siglos XVI y XVII», Arenal, 5.1, 1998, pp. 69-205.

Sánchez Lora, José Luis, Mujeres, conventos y formas de religiosidad barroca, Madrid, Fundación Universitaria Española, 1988. 
Sánchez Ortega, María Helena, La mujer y la sexualidad en el Antiguo Régimen: la perspectiva inquisitorial, Madrid, Akal, 1991.

Sarrión Mora, Adelina, Sexualidad y confesión. La solicitación ante el Tribunal del Santo Oficio (siglos XVI-XIX), Madrid, Alianza Editorial, 1994.

Vargas, José María, «La verdad integral de sucesos históricamente desfigurados (1611-1612)», en Historia de la Iglesia Católica en el Ecuador, dir. Jorge Salvador Lara, Quito, Conferencia Episcopal Ecuatoriana, 2001, pp. 1019-1029.

Viforcos Marinas, María Isabel, «Las reformas disciplinares de Trento y la realidad de la vida monástica en el Perú virreinal», en Actas del II Congreso Internacional. El monacato femenino en el Imperio Español. Monasterios, beaterios, recogimientos y colegios, coord. Manuel Ramos Medina, México, Condumex, 1995, pp. 523-540.

Viforcos Marinas, María Isabel, «Semblanza de fray Juan González de Mendoza, embajador de Felipe II a China y obispo de Popoyán», Ciudad de Dios. Revista Agustiniana, 211.3, 1998, pp. 729-758. 